\title{
Prevalence and antimicrobial resistance pattern of bacterial strains isolated from patients with urinary tract infection
}

\begin{abstract}
The risk of morbidity and complications with urinary tract infection (UTI) are more common in women. Urinary tract infection (UTI) affects all age groups, but women particularly are more susceptible than men, due to short urethra, proximity of urethral orifice to anal opening and hence higher chances of contamination of urinary tract with fecal flora and various other reasons. To investigate the prevalence of urinary tract infection among patients at PES Institute of Medical Sciences \& Research centre, Kuppam, to identify the causative bacteria and to explore their resistance pattern to antimicrobials. This study was conducted with 500 cases of women attending for checkup. Midstream urine specimen was collected from these women and immediately processed for culture. Growths in those plates with significant bacteriuria were subjected to standard biochemical tests for identification and antimicrobial sensitivity. Out of the 500 specimens 68 (13.6\%) samples were positive, from which 11 different isolates in this study Predominant isolate under the gram negative bacteria was Escherichia coli in 28 cases (41.1\%) followed by Klebsiella pneumoniae in 9 cases $(13.2 \%)$, Pseudomonas aeruginosa 4 cases $(5.8 \%)$, Proteus mirabilis 4 cases $(5.8 \%)$, Citrobacter koseri 3 cases (4.4\%), Proteus vulgaris 3 cases (4.4\%), Klebsiella oxytoca 2 cases $(2.9 \%)$, Providencia rettgerii 2 cases $(2.9 \%)$ and under the gram positive bacteria Coagulase negative Staphylococcus (CONS) was predominant isolate in 6 case $(9.1 \%)$, Staphylococcus aureus in 5 cases $(7.3 \%)$ followed by Enterococcus faecalis 2 cases $(2.9 \%)$
\end{abstract}

Keywords: antimicrobial resistance, antimicrobial susceptibility testing (AST), significant bacteriuria, urinary tract infection (UTI), uropathogens, urine culture
Volume 5 Issue I - 2017

\author{
Priscilla R,' Latha G, ${ }^{2}$ Devaprasanna Rajan, ${ }^{2}$ \\ Munasira Sultana ${ }^{2}$ \\ 'Department of Microbiology, Heritage Institute of Medical \\ Sciences, India \\ ${ }^{2}$ Department of Microbiology, PES Institute of Medical Sciences \\ \& Research Centre, India
}

Correspondence: Priscilla R, Department of Microbiology, Heritage Institute of medical sciences, Varanasi, India, Email r.priscilla20I0@gmail.com

Received: October 01, 2016 | Published: February 07, 2017
Abbreviations: UTI, urinary tract infection; AST, antimicrobial susceptibility testing; CONS, coagulase negative staphylococcus

\section{Introduction}

Urinary tract infection (UTI) affects all age groups, but women particularly are more susceptible than men due to anatomical relationship of the urinary tract. The risk of complications due to UTI is more common in women, because UTI may be associated with asymptomatic Bacteriuria in women. Asymptomatic Bacteriuria is defined as the presence of actively multiplying bacteria within the urinary tract and culture reveals a significant growth of pathogens that is equal or greater than $10^{5}$ bacteria per $\mathrm{ml}$ of urine, at the time when the patient has no clinical symptoms of urinary tract infection. ${ }^{1-3}$ The potential adverse effects of the undiagnosed UTI leads to pyelonephritis and cystitis. In different studies the prevalence of significant Bacteriuria in women was reported as 3-20\%. ${ }^{1-15}$ Significant Bacteriuria is a microbial diagnosis based on the isolation of significant count of bacteria in a properly collected specimen of urine from women with symptoms of UTI. Urine culture is the standard test for diagnosing of UTI. This study was therefore undertaken to determine the prevalence and antimicrobial susceptibility pattern of bacterial strains isolated from patients with urinary tract infection women attending at PESIMSR, Kuppam.

\section{Material and methods}

A total of 500 women who do have clinical signs and symptoms of UTI with ages ranging from 18 to 45 years attending at PESIMSR during six month of period were included in this study. Women who were on antibiotic treatment two weeks prior those who having clinical signs and symptoms of urinary tract infection (UTI) were included for this study. Oral consent was taken from the patient and suitable instructions to collect mid stream urine in to the sterile container provided to them was given to all those patients. Specimen was transported to the Department of Microbiology, PESIMSR without delay and processed in the laboratory.

\section{Sampling and bacteriological analysis}

Specimen collection

Transport of specimen

Processing of specimen:

a. Direct microscopy

i. Wet mount

ii. Gram's stain

b. Semi quantitative culture method.

c. Screening test for urine.

\section{i. Specimen collection}

a. Mid-stream Specimen of Urine (MSU): Urine samples were collected by obtaining the mid-stream flow by the clean-catch technique. The midstream portion of urine is then collected in 
plastic sterile, wide-mouthed with a $12 \mathrm{OZ}(350 \mathrm{ml})$ container should be covered with a tightly fitted lid.

ii. Transport of specimen: Once collected, urine was transported to the laboratory without delay, for urine is an excellent culture media and contaminating bacteria can readily multiply to reach apparently significant numbers.

\section{iii. Processing of specimen}

\section{a. Direct microscopy}

i. Wet mount: A wet mount examined after centrifugation was done for detection of both pyuria and bacteriuria. Approximately $10 \mathrm{ml}$ of urine was centrifuged in a tube at $2500-3000 \mathrm{rpm}$ for 5 minutes. The supernatant was discarded and a drop of the deposit was placed on a slide. The drop was covered by a coverslip and observed under a high power objective for bacteriuria, the number of organism/HPF was examined (at least 10 organism/ HPF) while for pyuria, the number of pus cells per $20 \mathrm{HPF}$ were counted (more than 10 pus cells/20 HPF).

ii. Gram's stain: The sediment obtained by centrifuged urine for wet mount examination was used to prepare a smear on a slide, heat fixed and stained by Gram's staining technique. The slide was then observed under oil immersion objective for presence of bacteria and pus cells. Presence of 1 bacteria/oil immersion field was considered positive. At least 50 fields were examined before declaring the smear negative.

b. Semi quantitative culture: All the samples were inoculated on to Blood agar, MacConkey agar and Cystine Lactose Electrolyte Deficient (CLED) agar using calibrated loop as per the standard procedure for semi quantitative technique developed by kass for urine culture. Those culture plates with bacterial growth showing $10^{5}$ bacteria per $\mathrm{ml}$ of urine were taken up for further processing. Bacterial growth from those plates was identified using standard biochemical tests. Antimicrobial sensitivity was performed as per the Kirby - Bauer disc diffusion method using commercially available discs (Hi-media) on Muller-Hinton Agar plates. After overnight incubation, the zone of inhibition formed around each antibiotic disc was measured and interpreted as sensitive, intermediate and resistant.

\section{Results}

Out of 500 urine specimens processed in this study, 68(13.6\%) showed significant bacteriuria. Thus the prevalence of significant bacteriuria in women in this study was $13.6 \%$ (Table 1-3) (Figure 1-3).
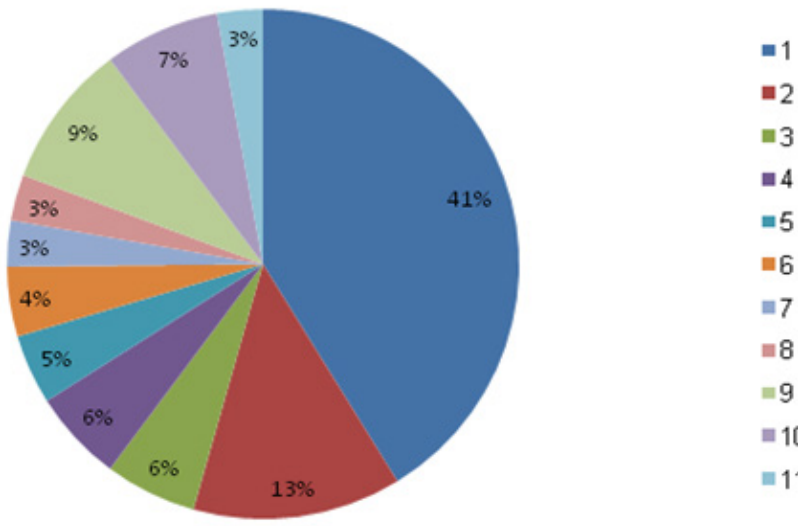

Figure I Details of isolates.

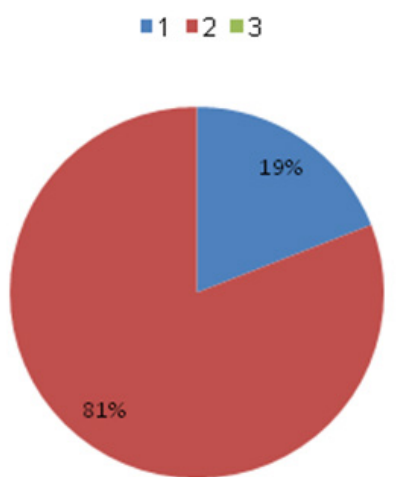

Figure 2 Isolates with respective group.

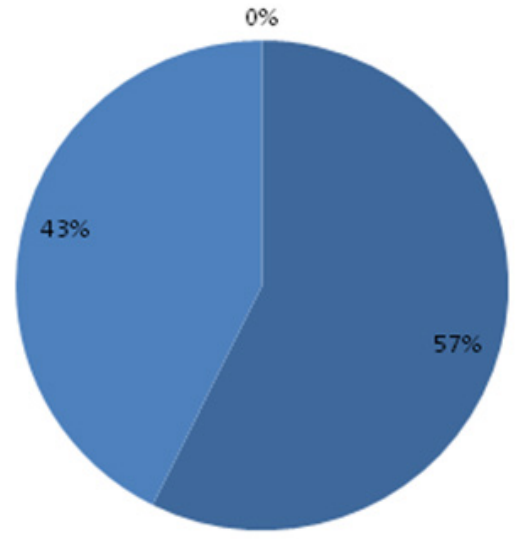

Table I Details of isolates

\begin{tabular}{lll}
\hline Name of the isolate & No. of isolates & Percentage $\mathbf{n}=68$ \\
\hline Escherichia coli & 28 & $41.10 \%$ \\
Klebsiella pneumoniae & 9 & $13.20 \%$ \\
Pseudomonas aeruginosa & 4 & $5.80 \%$ \\
Proteus mirabilis & 4 & $5.80 \%$ \\
Citrobacter koseri & 3 & $4.40 \%$ \\
Proteus vulgaris & 3 & $4.40 \%$ \\
Klebsiella oxytoca & 2 & $2.90 \%$ \\
Providencia rettgerii & 2 & $2.90 \%$ \\
CONS & 6 & $9.10 \%$ \\
Staphylococcus aureus & 5 & $7.30 \%$ \\
Enterococcus faecalis & 2 & $2.90 \%$ \\
\hline
\end{tabular}

Table 2 Distribution of isolates with respective group

\begin{tabular}{ll}
\hline Type of bacteria isolated & Total $\mathbf{n}=\mathbf{6 8}$ \\
\hline GPC & $13(19.1 \%)$ \\
GNB & $55(81.0 \%)$
\end{tabular}


Table 3 Age wise distribution and significant bacteriuria

\begin{tabular}{llll}
\hline Age group & $\begin{array}{l}\text { No. of } \\
\text { samples }\end{array}$ & $\begin{array}{l}\text { No. of } \\
\text { cases with } \\
\text { significant } \\
\text { bacteriuria } \\
\mathbf{n}=68\end{array}$ & Percentage \\
\hline 18- 25Years & 229 & 39 & $57.35 \%$ \\
26- 35Years & 270 & 29 & $42.64 \%$ \\
36- 45Years & 1 & 0 & 0 \\
\hline
\end{tabular}

\section{Discussion}

Urinary tract infections are remarkably common in women. Some $20 \%$ women in the age group 20-65years suffer from at least one attack per year, 50\% develop urinary tract infections within their life time. ${ }^{16}$ Not surprisingly infections of the urinary tract are the most common bacterial infections encountered in women. These can be both asymptomatic and symptomatic. UTI is a common and important medical condition, which will result in overt renal infections such as pyelonephritis, cystitis and other complications if not detected and treated. ${ }^{17,18}$ The prevalence of UTI among the women in this study was $13.6 \%$. Varying prevalence rates of significant bacteriuria in women were reported ranging from $3.3 \%$ to $23.9 \%$ depending on the population studied.

\section{Age}

The present study, it was observed that UTI in women at the age group 18-25years had highest percentage of infection $(57.35 \%)$ followed by $26-35$ years $(42.64 \%)$ and $36-45 y$ years $(0.50 \%)$. This is in contrast with in the study which was conducted by Girish babu et al., ${ }^{2}$ age group of 18-25years had highest percentage of infection $(60 \%)$. Turpin et al (2007) 6 also reported a high percentage of infection aged 35-45years. The observed trend of UTI in this study and reports from other studies shows the age range of 18-25years serving as a risk group for developing UTI women 8 .

\section{Isolates}

The most common bacterial isolate from women enrolled in this study was Escherichia coli in 28 cases $(41.1 \%)$ and followed by Klebsiella pneumoniae in 9 cases (13.2\%), Pseudomonas aeruginosa 4 cases $(5.8 \%)$, Proteus mirabilis 4 cases $(5.8 \%)$, Citrobacter koseri 3 cases $(4.4 \%)$, Proteus vulgaris 3 cases $(4.4 \%)$, Klebsiella oxytoca 2 cases $(2.9 \%)$, Providencia rettgerii 2 cases $(2.9 \%)$ and under the gram positive bacteria Coagulase negative Staphylococcus (CONS) was predominant isolate in 6 case $(9.1 \%)$, Staphylococcus aureus in 5 cases $(7.3 \%)$ followed by Enterococcus faecalis 2 cases $(2.9 \%)$. This is similar to many studies conducted in the past. Gram positive organisms have also received more attention as causative agents of urinary tract infection. Coagulase negative Staphylococcus (CONS) was second most common isolate in 6 cases $(9.1 \%)$, Staphylococcus aureus was in 5 cases $(7.3 \%)$ and Enterococcus faecalis in 2 cases $(2.9 \%)$ were under Gram positive organisms. This is correlated with the reports of previous studies.

\section{Antibiotics}

In the present study analysis of antimicrobial sensitivity pattern shows that among the 13 isolates of gram positive cocci, they were sensitive to Vancomycin (100\%), followed by Nitrofurantoin (92\%),
Amikacin (64\%), Gentamicin (55\%), Norfloxacin (50\%), Cotrimoxazole $(42 \%)$, Clindamycin $(28 \%)$, Amoxycillin/clavulinic acid (25\%) and Ciprofloxacin (15\%). Analysis of antimicrobial sensitivity pattern among 55 isolates of gram negative bacilli, they were sensitive to Imipenem (100\%), Amikacin (93\%), Nitrofurantoin (92\%), Norfloxacin (30\%), Ciprofloxacin (23\%), Cefotaxime (23\%), Amoxycillin/clavulinic acid (23\%) and Co-trimoxazole (13\%). ${ }^{19-23}$

\section{Conclusion}

UTI in women if not detected and treated may be a cause for significant morbidity in women. Various studies including this study was identified that prevalence of UTI is a real problem among women. It may be a good practice to undertake mandatory screening of all cases attending to hospital for UTI and accordingly the management of positive cases to avoid complication later in the life. UTI can be ascertained on the basis of microscopy and microbial culture. Thus urine culture is the gold standard screening technique for UTI. Our study showed $13.6 \%$ significant bacteriuria in women on screening by culture. Gram negative organisms were the commonest organisms isolated; among which Escherichia coli was the principle urinary pathogen. The isolates were most sensitive to Imipenem, Nitrofurantion, Amikacin, Piperacillin/tazobactam, Cefotaxime and Ciprofloxacin. All the isolates were least sensitive to Nalidixic acid, Co-Trimoxazole, Cefepime.

\section{Acknowledgements}

None.

\section{Conflict of interest}

The author declares no conflict of interest.

\section{References}

1. Lavanya SV, Jogalakshmi D. Prevalence of bacteriuria in women. Indian J med Microbiol. 2002;20:105-108.

2. Girishbabu RJ, Srikrishna R, Ramesh ST. Asymptomatic bacteriuria in pregnancy. Int J Biol Med Res. 2011;2(3):740-742.

3. Imade PE, Izekor PE, Eghafona NO, et al. Asymptomatic bacteriuria among pregnant women North. Am J Med Sci. 2010;2(6):263-266.

4. Yashodhara P, Mathur R, Raman L. Urinary tract infection in women. Indian J Med Res. 1987;86:309-314.

5. Roy SK, Sinha GR, Quadros M. A study of bacteriuria in pregnancy. $J$ Obstet Gynecol India. 1974;24:244-250.

6. Turpin CA, Bridget Minkah, Danso KA, et al. Asymptomatic bacteriuria in pregnant women attending antenatal clinic at komfo anokye teaching hospital, kumasi. Ghana Med J. 2007;41(1):26-29.

7. Jayalakshmi J, Jayaram VS. Evaluation of various screening tests to detect asymptomatic bacteriuria in pregnant women. Indian J Pathol Microbiol. 2008;51(3):379-381.

8. Abdullah AA, AI-Moslih MI. Prevalence of asymptomatic bacteriuria in pregnant women in Sharjah, United Arab Emirates. East Mediterr Health J. 2005;11(5-6):1045-1052.

9. Felice D, Garingalo-Molina. Asymptomatic Bacteriuria Among Pregnant Women. Phil J Microbiol Infect Dis. 2000;29(4):177-186.

10. Obirikorang C, Quaye L, Bio FY, et al. Asymptomatic Bacteriuria among Pregnant Women Attending Antenatal clinic at the University Hospital, Kumasi, Ghana. Journal of Medical and Biomedical Sciences. 2012;1(1):38-44. 
11. Platt R. Quantitative definition of bacteriuria. Am $J$ Med. 1983;75(1B):44-52.

12. Akram M, Shahid M, Khan AU. Etiology and antibiotic resistance patterns of community acquired urinary tract infection in JNMC hospital Aligarh, India. Ann Clin Microbiol Antimicro. 2007;4:23-26.

13. Leigh DA, Williams JD. Method for detection of significant bacteriuria in large group of patients. J Clin Pathol. 1964;17:498-503.

14. Sharifa A, AI Sibiani. Asymptomatic bacteriuria in pregnant women in Jeddah, Western Region of Saudi Arabia: Call for Assessment. JKAU Med Sci. 2009;17(1):29-42.

15. Dalzell JE, Lefevre ML. Urinary tract infection during pregnancy. Am Fam Physician. 2000;61(3):713-721.

16. Gilstrap LC, Leveno KJ, Cunningham FG, et al. Renal infection and pregnancy outcome. Am J Obset Gynecol. 1981;141(6):709-716.

17. Gratacos E, Torres PJ, Vila J, et al. Screening and treatment of asymptomatic bacteriuria in pregnancy prevent pyelonephritis. J Infect Dis. 1994;69(6):1390-1392.
18. Saeed S, Tariq P. Symptomatic and Asymptomatic Urinary Tract Infections during pregnancy. Intl J Microbiol Res. 2011;2(2):101-104.

19. Akinloye O, Ogbolu DO, Akinloye OM, et al. Asymptomatic bacteriuria in pregnancy in Ibadan, Nigeria: a re-assessment. Br J Biomed Sci. 2006;63(3):109-112.

20. Roberts AP, Phillips R. Bacteria causing symptomatic urinary tract infection or asymptomatic bacteriuria. J Clin Pathol. 1979;32(5):492496.

21. Schnarr J, Smaill F. Asymptomatic bacteriuria and symptomatic urinary tract infections in pregnancy. Eur J Clin Invest. 2008;38(S2):50-57.

22. Perera J, Randeniya C, Perera P, et al. Asymptomatic Bacteriuria in Pregnancy: Prevalence, Risk factors and Causative Organisms. Sri Lankan Journal of Infectious Diseases. 2012;1(2):42-46.

23. Sussman M. Urinary tract infections. In: Topley, Wilson, editors. Microbiology and Microbial Infections. 9th ed. London: Arnold; 1998. p. $601-621$. 